\title{
Quantitative Analysis Using Asymmetric Adaptive Pulse Processing
}

\author{
Richard B. Mott ${ }^{1}$, Owen E. Healy ${ }^{1}$, Nicholas W. M. Ritchie ${ }^{2}$, and Abigail P. Lindstrom ${ }^{2}$ \\ ${ }^{1}$ PulseTor LLC, 1580 Reed Road, Suite C2, Pennington NJ 08534 \\ 2 National Institute of Standards and Technology, Gaithersburg, MD 20899-8371
}

Previous work [1] demonstrated that pulse-by-pulse adaptive digital filtering improves the precision of $\mathrm{X}$-ray quantitative analysis for a given sample electron dose, with no loss of accuracy compared to conventional pulse processing. The improvement stems from better energy resolution compared to short fixed digital filtering for the same throughput. The gain in precision is greatest for small peaks below about $5 \mathrm{keV}$ near to or overlapping with larger peaks, such as Al in NIST K412 glass, which has favorable implications for analysis at low accelerating voltages.

That work used only a small set of digital filters for ease of generating standards. The time intervals between X-ray arrivals are randomly unequal. Asymmetric processing, as described by Koeman [2], reduces the noise component of resolution by allowing different integration times before and after an Xray arrives. It promises further gains in analytical precision, but it also requires more sophisticated peak shape modeling to derive appropriate fitting spectra from standards.

Table 1 shows the resolution gained by asymmetrical filtering. The matrix diagonal is conventional symmetric filtering (shaded). Entries in bold are the filters used for last year's results. The axes are leading and trailing integration times in $\mathrm{nS}$. Entries are $\mathrm{Al}-\mathrm{K}$ resolution in an $\mathrm{Al}_{2} \mathrm{O}_{3}$ sample at $7 \mathrm{nA}, 319$ kcps input rate, $196 \mathrm{kcps}$ throughput rate. Figure 1 is a resolution contour plot of these data.The matrix is symmetric within a few tenths of an $\mathrm{eV}$, which is expected since resolution should not depend on arrival order for each pair of intervals. For each diagonal entry, resolution improves as we move up or to the right (increasing the integration time toward the wider interval).

Table 2 gives the probability of occurrence for each of the cells in Table 1 at an input count rate of 320 kcps. The interval pair probability depends only on the input rate, regardless of the composition of the sample. At $320 \mathrm{kcps}$ ICR and $38 \%$ dead time, nearly $27 \%$ of the X-rays fall in the upper right matrix cell with six times the integration period and $30 \mathrm{eV}$ better resolution relative to the shortest filter, while $77 \%$ are measured with $2.4 \mathrm{uS}$ integration on one side (top row or right column).

The table sums to 1, and the lower-left entries are so small because the time bins are of unequal size. The rectangle with each diagonal entry at a lower left corner sums to the fraction of X-rays measured with that diagonal entry's resolution or better. Since the input rates generated from the unknown and the standards will be different in general, the procedure for generating fitting standards uses the noise components derived from Table 1 with the probabilities of Table 2, which can be readily computed for any input count rate.

\section{References}

[1] R.B. Mott, O.E. Healy, N.W.M. Ritchie and A.P. Lindstrom. Microscopy and Microanalysis 19 (Suppl. 2), (2013) 1252-1253.

[2] H. Koeman, Nuclear Instruments and Methods 123, (1975) 161-167. 


$\begin{array}{rrrrrrrrrrr}2400 \mathrm{nS} & 97.6 & 94.4 & 91.9 & 88.9 & 86.7 & 85.1 & 83.9 & 82.6 & 82.0 & 81.8 \\ 2000 \mathrm{nS} & 97.9 & 94.9 & 92.3 & 89.1 & 87.0 & 85.7 & 84.2 & 83.0 & 82.4 & 81.9 \\ 1600 \mathrm{nS} & 98.3 & 95.5 & 93.0 & 89.9 & 87.7 & 86.3 & 84.9 & 83.8 & 83.0 & 82.6 \\ 1280 \mathrm{nS} & 99.3 & 96.2 & 93.9 & 90.8 & 88.8 & 87.3 & 85.9 & 84.9 & 84.1 & 83.7 \\ 1040 \mathrm{nS} & 100.2 & 97.3 & 94.9 & 91.8 & 90.0 & 88.6 & 87.4 & 86.2 & 85.7 & 85.4 \\ 880 \mathrm{nS} & 101.4 & 98.2 & 96.2 & 93.2 & 91.0 & 89.9 & 88.4 & 87.6 & 86.8 & 86.7 \\ 720 \mathrm{nS} & 103.0 & 100.0 & 97.8 & 95.0 & 93.1 & 91.9 & 90.7 & 89.8 & 88.9 & 88.9 \\ 560 \mathrm{nS} & 105.7 & 102.7 & 100.5 & 97.9 & 96.3 & 95.0 & 93.8 & 92.9 & 92.3 & 92.1 \\ 480 \mathrm{nS} & 107.7 & 104.9 & 102.6 & 100.1 & 98.2 & 97.4 & 96.1 & 95.0 & 94.5 & 94.4 \\ 400 \mathrm{nS} & \mathbf{1 1 0 . 3} & 107.4 & 105.6 & 102.7 & 101.3 & 100.2 & 99.3 & 98.4 & 97.7 & 97.4 \\ \text { Filters } & 400 & 480 & 560 & 720 & 880 & 1040 & 1280 & 1600 & 2000 & 2400 \\ & \mathrm{nS} & \mathrm{nS} & \mathrm{nS} & \mathrm{nS} & \mathrm{nS} & \mathrm{nS} & \mathrm{nS} & \mathrm{nS} & \mathrm{nS} & \mathrm{nS}\end{array}$

Table 1. Al-K resolution vs. filter times. Diagonal (shaded) entries are symmetric filtering. Resolution improves above and to the right of each diagonal entry, as leading (row) or trailing (column) integration times increase.

$\begin{array}{rrrrrrrrrrr}2400 \mathrm{nS} & 0.0134 & 0.0130 & 0.0252 & 0.0239 & 0.0227 & 0.0319 & 0.0388 & 0.0428 & 0.0373 & 0.2687 \\ 2000 \mathrm{nS} & 0.0019 & 0.0018 & 0.0035 & 0.0033 & 0.0032 & 0.0045 & 0.0055 & 0.0063 & 0.0056 & 0.0373 \\ 1600 \mathrm{nS} & 0.0021 & 0.0021 & 0.0040 & 0.0038 & 0.0036 & 0.0051 & 0.0063 & 0.0069 & 0.0063 & 0.0429 \\ 1280 \mathrm{nS} & 0.0019 & 0.0019 & 0.0037 & 0.0034 & 0.0033 & 0.0046 & \mathbf{0 . 0 0 5 6} & 0.0063 & 0.0055 & 0.0388 \\ 1040 \mathrm{nS} & 0.0016 & 0.0016 & 0.0030 & 0.0028 & 0.0027 & 0.0038 & 0.0046 & 0.0051 & 0.0045 & 0.0319 \\ 880 \mathrm{nS} & 0.0011 & 0.0011 & 0.0021 & 0.0020 & 0.0019 & 0.0027 & 0.0033 & 0.0036 & 0.0032 & 0.0227 \\ 720 \mathrm{nS} & 0.0012 & 0.0012 & 0.0022 & \mathbf{0 . 0 0 2 1} & 0.0020 & 0.0028 & 0.0035 & 0.0038 & 0.0034 & 0.0239 \\ 560 \mathrm{nS} & 0.0013 & 0.0012 & 0.0024 & 0.0022 & 0.0021 & 0.0030 & 0.0037 & 0.0040 & 0.0036 & 0.0252 \\ 480 \mathrm{nS} & 0.0007 & 0.0006 & 0.0012 & 0.0012 & 0.0011 & 0.0016 & 0.0019 & 0.0021 & 0.0018 & 0.0131 \\ 400 \mathrm{nS} & \mathbf{0 . 0 0 0 7} & 0.0006 & 0.0013 & 0.0012 & 0.0011 & 0.0016 & 0.0019 & 0.0022 & 0.0019 & 0.0135 \\ \text { Filters } & 400 & 480 & 560 & 720 & 880 & 1040 & 1280 & 1600 & 2000 & 2400 \\ & \mathrm{nS} & \mathrm{nS} & \mathrm{nS} & \mathrm{nS} & \mathrm{nS} & \mathrm{nS} & \mathrm{nS} & \mathrm{nS} & \mathrm{nS} & \mathrm{nS}\end{array}$

Table 2. Probability for measured X-rays falling into each cell in Table 1.

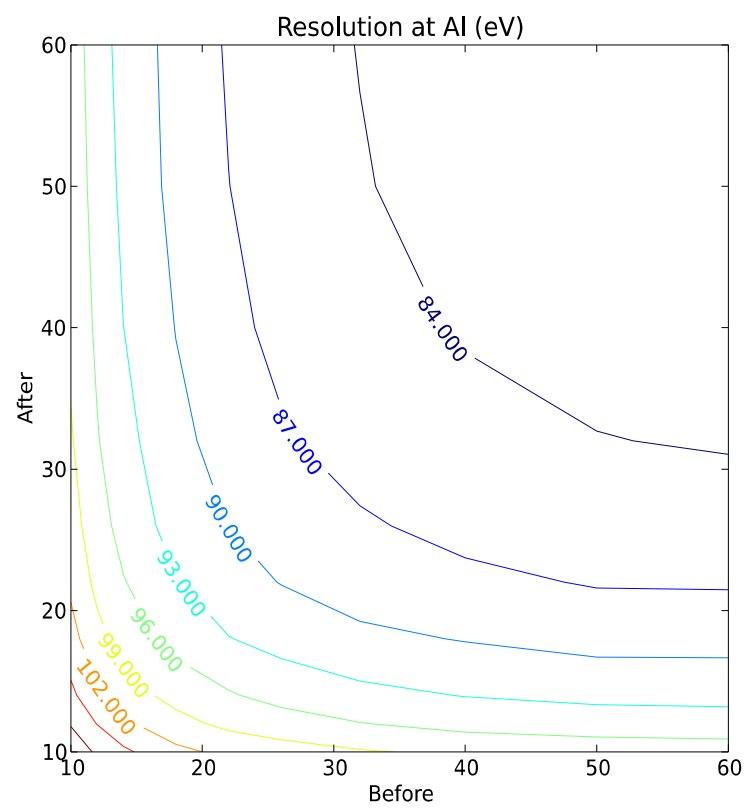

Figure 1. Table 1 as resolution contour plot. 